Citation: Eroglu, E., Bozkurt, E., Esenpinar, A.A., Tek, S., "Mathematical Analysis Of Covid-19 Phenomenon". 5 (2) 2020 : 59-64.

\title{
MATHEMATICAL ANALYSIS OF COVID-19 PHENOMENON
}

\author{
Emre Eroglu $^{a^{*}}$ (D) Eshabil Bozkurt ${ }^{\mathrm{b}}$ (D), Aliye Asli Esenpinar ${ }^{\text {(D) }}$, Suleyman Tek ${ }^{\mathrm{d}}$ \\ ${ }^{a}$ Department of Research and Development, Armoya High Technology Institute \\ eroglumre@gmail.com (*corresponding author) \\ ${ }^{b}$ Department of Translation and Interpreting, Kirklareli University \\ eshabilbozkurt@gmail.com \\ ${ }^{c}$ Department of Chemistry, Kirklareli University \\ asliesenpinar@gmail.com \\ ${ }^{d}$ Department of Mathematics, University of the Incarnate Word \\ suleymantek@gmail.com
}

\begin{abstract}
The epidemic is defined as a disease that affects the huge majority of the world, massively infecting people and causing deaths. Negative effects, number of casualties, spreading speeds and start-to-finish time of these outbreaks are different. This difference depends on the domains, the process of vaccination studies, and cured. Today, the virus that causes the world-threatening epidemic is COVID-19. One can find the handling of COVID-19 cases with the SIR (susceptible-infected-recovered) Mathematical Model in the essay. The study carefully examines data from worldometers, establishes the SIR Model, estimates the number of infected people cases in China and South Korea.
\end{abstract}

Keywords: SIR dynamic system, mathematical modeling, COVID-19

\section{Introduction}

Throughout history, mankind experienced many epidemic diseases [8], which are called a pandemic and hundreds of thousands even millions of people died due to these pandemics. Millions of people died in the last two centuries because of some epidemic diseases such as Spanish Flu [7], HIV [11], Ebola [9], Swine Flu [10], Bird Flu [4,5], COVID-19 which is the last link in this chain of outbreaks was seen first in the last month of 2019 in Wuhan, China. This epidemic, which spread all over the world immediately was stated a pandemic by the World Health Organization (WHO) on March 11, 2020. According to the data of WHO the pandemic spread to 213 countries infect 2.314 .621 people and 157.847 people died due to 
coronavirus until April 20, 2020. Both economic and medical measures are taken to prevent its negative effects all over the world. To struggle with the disease has fatal consequences [13], and it spreads so rapidly.

In the early 1700s, Bernoulli was the first scientist to guide the door to mathematical epidemiology. This area, whose scientific foundation was laid at the beginning of the 20th century, was particularly influential on decision-making mechanisms with the accurate discussions and consistent analysis of mathematicians. Dynamic systems, which are one of the main factors of this positive effect, are named with SI, SIS, SIR, SIRS, SEIR, SEIS, SEIR, MSIR, MSEIR models.

The SIR Mathematics Model [12,6] is a dynamic system model that contains susceptible, infected, and recovered dependent variables that evolve over time. This system consists of three basic autonomous differential equations. The advantage of the model is that it can predict the number of infected patients with high accuracy. Two parameters called infected and recovered constants are utilized in the solution of the equation. With the SIR epidemic model, mathematics guides scientists against the COVID-19 process in studies related to the virus $[2,3]$.

This essay is based on the data of worldometer [1]. The data in the study are those declared between April 01 and April 30, 2020. These data are investigated by the SIR Mathematical Model including the number of infected people of China and South Korea. The study commences with the SIR epidemic model, afterward, it endures by the solution of the equation system. The solution of the dynamic system is handled with Euler's iteration method. Lastly, it concludes with the Reproduction Number $\left(\mathrm{R}_{0}\right)$ and graphics of China and South Korea.

\section{Materials and methods}

The SIR autonomous differential system is employed in epidemiology to calculate the number of susceptible, infected, recovered people in a population. It is a proper one to utilize under the following pre-accepted:

i. The population is fixed.

ii. The just one alternative a person can leave the susceptible set is to convert infected. The just one alternative a person can leave the infected group is to recover from the disease. Once a person has recovered, the (s)he gains immunity.

iii. The population number is accepted homogeneous.

$$
\begin{aligned}
& \frac{d S}{d t}=-\beta S(t) I(t) \\
& \frac{d I}{d t}=\beta S(t) I(t)-f I(t) \\
& \frac{d R}{d t}=f I(t)
\end{aligned}
$$

where $\mathrm{S}(\mathrm{t})$ is susceptible, $\mathrm{I}(\mathrm{t})$ is infected and $\mathrm{R}(\mathrm{t})$ is recovered. All of individual variable evolve over time (time-dependent). $\beta>0$ is the rate of transition from susceptible person to infected person in the time, $f>0$ is the recovery speed. The SIR Model is an autonomous problem. The model doesn't include demographic factor, birth, death, migration and the model diagram (Figure 1) flow is to the right side, there is no pass to the left side. $\mathrm{N}$ is the total population, $N=S(t)+I(t)+R(t), t>0$ and $S(0)>0, I(0)>0, R(0)>0$ (If $t_{0}=0$ is taken as the start time of the pandemic, $R(0)=0$ should be. However, the author takes to start as April 01 . 
Assume that leaving people value from the susceptible is equal to incoming infected people's values. When time $t$ diverges to infinity then $\lim _{t \rightarrow \infty} S(t)=0, \lim _{t \rightarrow \infty} R(t)=N$.

In order to solve the differential equation can be utilized Euler's method for dynamic systems:

$S_{n+1}=S_{n}-\beta S_{n} I_{n} \Delta t$

$I_{n+1}=I_{n}\left(1+\beta S_{n}-f\right) \Delta t$

$R_{n+1}=R_{n}+f I_{n} \Delta t$

where $\Delta t=t_{n+1}-t_{n}$ is a minor change in time and $S_{n+1}, I_{n+1}, R_{n+1}$ are susceptible, infected and recovered people, respectively. For the iteration, $\beta$ and $f$ coefficients have to be known. With the determination of proper $\beta$ and $f$ constants and evolution of time, one can estimate total infected and recovered people.

The advantage of the SIR Mathematics Model is that with the aid of infection and recovery coefficients the number of infected people can be estimated. The model gives mathematicians the opportunity to determine the status of the infection. The weakness of the model is that it cannot provide a projection of the number of people died.

\section{Results and discussion}

In this section, the iteration (from eq.4-5) time of the data of China and South Korea is April. These country population data belong to the range of 01 April 2020 - 30 April 2020. The total number of infected patients is estimated from the data that are subjected to iteration day by day for a month. Of course, the 30-day iteration period is not very long. It may be more appropriate to take the months of March or February instead of April. However, the paper does not need this because the error rates are not high and they decrease towards the end of the iteration. Table 1 and Table 2 indicate the coefficients infected ratio $\beta$ and recover ratio $f$ and exhibits the real infected people numbers and predicted infected people numbers for the six days that selected from the one-month estimation values, the error rates of these estimates. Figure 1 and Figure 2 illustrate infected numbers and estimated numbers of people of China and South Korea, respectively.

Table 1. Infected people real values and predicted values (China)

\begin{tabular}{cccccc}
\hline Day & Real value & $\begin{array}{c}\text { Estimated } \\
\text { value }\end{array}$ & (\%) Error & $\beta$ & $f$ \\
\hline 01 April & 81589 & 81620 & 0.04 & & \\
10 April & 81953 & 82052 & 0.12 & & \\
18 April & 82719 & 82735 & 0.02 & $3.23 \times 10^{-11}$ & \\
23 April & 82798 & 82804 & 0.02 & & \\
27 April & 82830 & 82836 & 0.01 & & \\
30 April & 82862 & 82871 & 0.01 & & \\
\hline
\end{tabular}




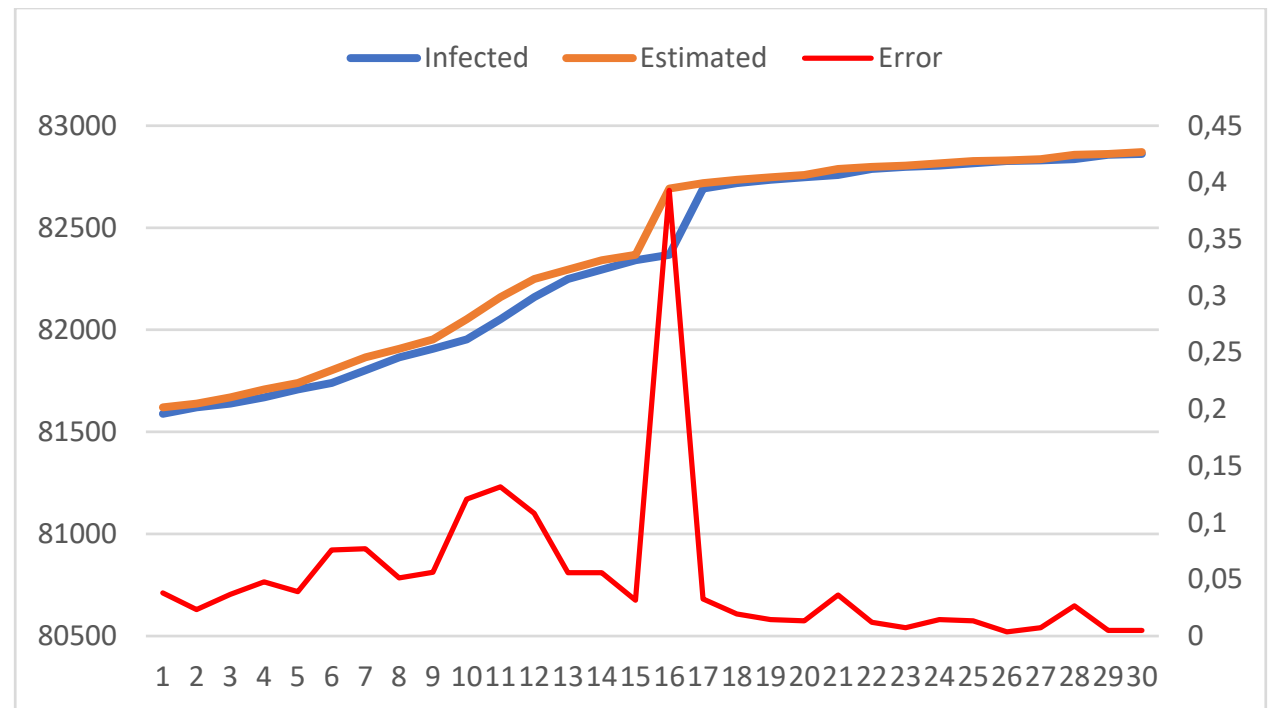

Figure 1. Total infected and estimated values pattern, China

If one discusses the results of the 30-day projection for China during April, (s)he can see that the error ratio of the estimated number of infected people is satisfactory. Six days randomly selected from one month can be noticed in Table 1.

Table 2. Infected people real values and predicted values (South Korea)

\begin{tabular}{cccccc}
\hline Day & Real value & $\begin{array}{c}\text { Estimated } \\
\text { value }\end{array}$ & (\%) Error & $\beta$ & $f$ \\
\hline 01 April & 9887 & 10246 & 3.50 & & \\
10 April & 10450 & 10480 & 0.29 & & \\
18 April & 10653 & 10661 & 0.08 & $8.73 \times 10^{-9}$ & \\
23 April & 10702 & 10708 & 0.06 & & \\
27 April & 10738 & 10752 & 0.13 & & \\
30 April & 10765 & 10768 & 0.03 & \\
\hline
\end{tabular}

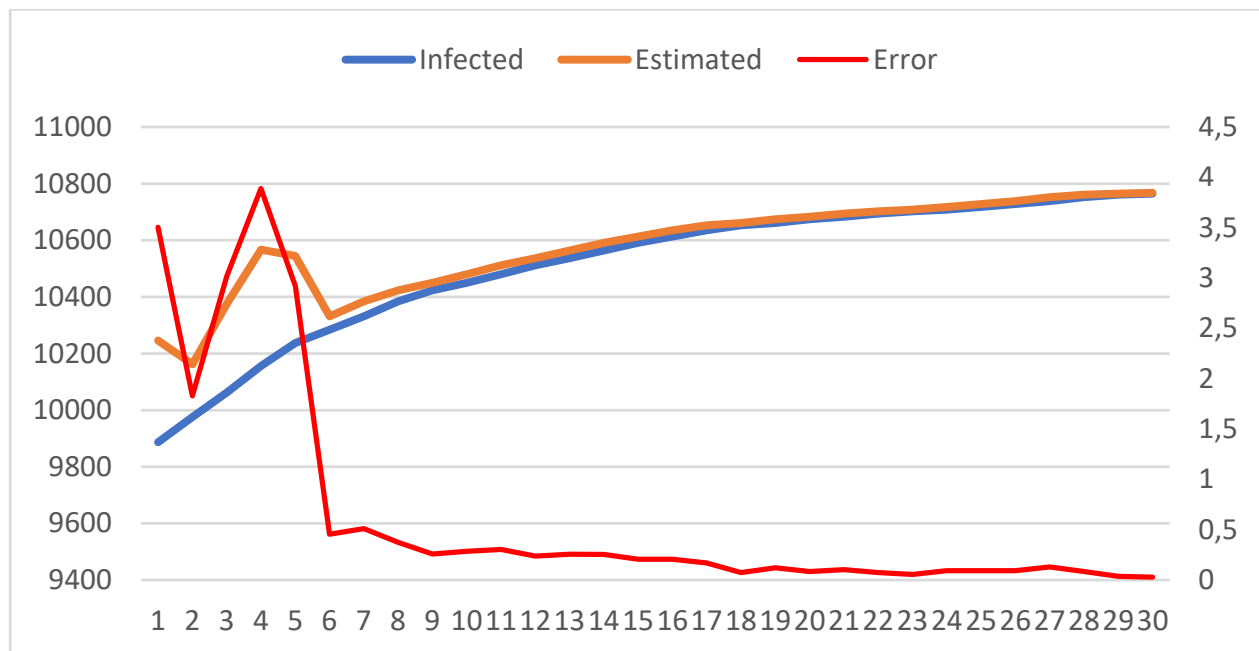

Figure 2. Total infected and estimated values pattern, South Korea 
If one looks at the results of the 30-day projection for South Korea during April, (s)he can realize that the error ratio of the estimated amount of infected people is acceptable even it is higher than China. Six days randomly selected from one month can be noticed in Table 2. Errorvalues percentages decrease day by day.

The SIR Model has a notice about the continuation of the pandemic process, in addition to consistent evaluations with current data. Reproduction Number $\left(\mathrm{R}_{0}\right)$ includes in the discussion just now. The number $\mathrm{R}_{0}$ means that: $R_{0}=\frac{\beta}{f} S_{0}$, where $\beta$ is infected rate, $f$ is recover rate, and $\mathrm{S}_{0}$ is the first susceptible people number. Reproduction Number estimates whether the population's risk in the infection process continues. If $R_{0}>1$, the risk of infection continues, if $R_{0}<1$, the risk of infection decreases and ends. If $R_{0}=1$, disease risk remains constant.

China's $\mathrm{R}_{0}$ value is 1.51 and South Korea's 1.24 . Consequently, the danger doesn't eliminate over, although the number of new cases is brought under control in both countries.

\section{Conclusions}

The paper examines, models, and forecasts cases of the COVID-19 via the SIR Mathematical Model. The results of the discussion by the aid of the mathematical approach are revealed. Although the world (Total) virus cases are still far from the peak value, China and South Korea succeed the fight to the virus. Because of this situation, the essay handles these countries and it estimates total infected cases using the SIR model. The model has an autonomous dynamic system. Euler's iteration is a suitable method for solving the differential equation. The results of the discussion may guide people about infected people. Outcomes of China are indicated to the reader with less than two percent error ratio. South Korea's infected people numbers are also displayed with decreasing about four percent error ratio by the SIR epidemic model. Although the struggle of the two countries with the pandemic is admirable, the high $\mathrm{R}_{0}$ values indicate that they have to continue to act cautiously. The authors try to investigate other countries with this model. They hope that these estimations for infected cases aid for the understanding of the spreading of the pandemic.

\section{Acknowledgement}

We thank The Max Planck Institute for Dynamics and Self-Organization at Göttingen, Germany. This paper is dedicated to the healthy days in the future.

\section{References}

[1] Anonymous, https://www.worldometers.info/ (30 April 2020).

[2] Toda, A.A., "Susceptible-Infected-Recovered (SIR) Dynamics of COVID-19 and economic impact”, https://arxiv.org/abs/2003.11221.

[3] Ndiaye, B.M., Seck, L.T.D., "Analysis of the COVID-19 pandemic by SIR model and machine learning technics for forecasting”, https://arxiv.org/abs/2004.01574.

[4] Lahariya, C., Sharma, A.K., Pradhan, S.K., “Avian flu and possible human pandemic”, Indian Pediatrics 43 (4) (2006) : 317-325, https://www.ncbi.nlm.nih.gov/pubmed/ 16651670. 
[5] Cetin, E., Kiremitci, T., "Matematiksel epidemiyoloji: Pandemik A/H1N1 gribi vakası", Journal of the School of Business Administration 38 (2009) : 197-209 (in Turkish).

[6] Keeling, M.J., Rohani, P., “Modeling infectious diseases in human and animals”, Princeton University Press, Princeton, (2007).

[7] Worobey, M., Rambaut, A., Pybus, O.G., Robertson, D.L., Gibbs, M.J., Armstrong, J.S., Gibbs, A.J., "Questioning the evidence for genetic recombination in the 1918 Spanish Flu virus”, Science. 296 (5566) (2000).

[8] Saunders-Hastings, P.R., Krewski, D., "Reviewing the history of pandemic influenza: understanding patterns of emergence and transmission”, Pathogens. 5 (4) (2016) : 66.

[9] Hall, R.C.W., Chapman, M.J., "The 1995 Kikwit Ebola outbreak: lessons hospitals and physicians can apply to future viral epidemics”, General Hospital Psychiatry 30 (5) (2008) : 446-452.

[10] Cousins, S., "Death toll from swine flu in India exceeds”, BMJ 2500 (2015) : 351.

[11] Adih, W.K., Selik, R.M, Hall, H.I., Babu, A.S., Song, R., “Associations and trends in cause-specific rates of death among persons reported with HIV infection, 23 U.S. jurisdictions, through 2011”, The Open AIDS Journal 19 (2016) : 144-157.

[12] Kermack, W.O., McKendrick, A.G., "A contribution to the mathematical theory of epidemics”, Proceeding of the Royal Society A 115 (772) (1927).

[13] Xu, Z., Shi, L., Wang, Y., Zhang, J., Huang, L., Zhang, C., "Pathological findings of Covid-19 associated with acute respiratory distress syndrome”, The Lancet 8 (4) (2020) : 420-422. 